\title{
Quality Management Systems and Organizational Performance: A Theoretical Review in Kenya's Public Sector Organizations
}

\author{
Zipporah Karimi Muiruri \\ Department of Commerce and Economics Studies, Jomo Kenyatta University of Agriculture and Technology, Nairobi, Kenya
}

\section{Email address:}

zippy.karimi@gmail.com

\section{To cite this article:}

Zipporah Karimi Muiruri. Quality Management Systems and Organizational Performance: A Theoretical Review in Kenya's Public Sector Organizations. Science Journal of Business and Management. Vol. 4, No. 5, 2016, pp. 150-155. doi: 10.11648/j.sjbm.20160405.12

Received: August 25, 2016; Accepted: September 1, 2016; Published: September 18, 2016

\begin{abstract}
Total Quality Management (TQM) has become an accepted technique to ensure performance and survival in the modern economies. In order to facilitate and impact the quality issues globally, the International Organization for Standardization (ISO) was first published in 1987 and was subsequently revised in 1994, 2000 and 2008. The ISO 9001 standards is a quality management standards that embraces principles of TQM and which merges organizational concerns with customer satisfaction, shareholder satisfaction, process efficiency, and employee wellbeing. The study focuses on customer satisfaction, employee engagement, productivity and management control. The paper reviewed the following theories: Expectancy-Disconfirmation Paradigm (EDP) as the most promising theoretical framework for the assessment of customer satisfaction; Herzberg motivation theory; Systems theory which consists of inputs, a transformation process, outputs, feedback and the environment and Henry Fayol's administrative theory of management which focuses on the entire organization. The study adopted a conceptual research design approach using secondary data. Conceptual analysis was used to draw inferences from QMS studies' findings in public and private sectors and in both goods and services industries keenly after a thorough examination. The purpose of the paper is to review the extant multidisciplinary based literature on quality management to propose a theoretical model relating quality management practices and firm performance. The paper focused on three objectives. Firstly, it sought to review the extant theoretical literature on the construct of quality management. Secondly, it identified relevant supporting theories to the construct of quality management. Thirdly the paper proposed a theoretical model for explaining the relationship between quality management and performance in diverse environmental contexts.
\end{abstract}

Keywords: Quality Management, Quality Management Systems, Firm Performance,

Multidisciplinary Theoretical Framework

\section{Introduction}

In the current business environment there is increasing pressure on firms by both consumers and competitors alike to continually innovate in new products and to upgrade the quality of existing goods and services. Quality setback is a burning and an endeavor issue that organizations make every effort in order to succeed and survive in a competitive world. Currently, the main concern of any organization is to reach the world class excellence through high quality products and services, customer satisfaction, and cost reduction with profit optimization [1]. TQM integrates fundamental management techniques, resources, and its implementation stands as a challenge and support to top management. Recent studies have claimed that successful implementation of TQM could generate improved products and services, as well as reduced costs, more satisfied customers and employees, and improved financial performance [2].

ISO is the world's largest developer and publisher of international standards. The ISO 9001 standards is a quality management standard that embraces principles of TQM and which merges organizational concerns with customer satisfaction, shareholder satisfaction, process efficiency, and employee wellbeing [3]. ISO 9001 encompasses organizational practices across sectors with its application being relevant to organizations regardless of the business 
they are in. This has made this particular certification relevant to most organizations thus gaining most popularity compared to other ISO standards. ISO 9001 provides a tried and tested framework for taking a systematic approach to managing business practices to consistently turn out quality products. ISO 9001 encompasses organizational practices across sectors with its application being relevant to organizations regardless of the business they are in. This has made this particular certification relevant to most organizations thus gaining most popularity compared to other ISO standards.

A 2012 survey of certifications [4] shows that Kenya has the highest number of organizations in East Africa achieving ISO certification. In 2012 there were 460 organizations with ISO 9001 certification (quality); 32 organizations with ISO 14001 certification (environment) and 118 organizations with ISO 22000 certification (food safety). ISO 9001 leads the pack and also has highest rate of conversion from non-certified to certified organizations over the last 10 years. Trade is a crucial driver of growth ([5]. For Kenya to achieve the double-digit economic growth envisaged in Vision 2030 [6], the country must be able to respond to local and global market demands. Kenya, just like many African countries, is confronted by a myriad of challenges in improving its capacity to meet production and quality standards which are obligatory to access foreign markets, especially the European Union which is one of Kenya's biggest trading partners. Nicholas Stern, the former World Bank chief economist and senior vice president, notes that without addressing market access and international standards compliance issues, African firms and farmers will be unable to take full advantage of market opening initiatives. ISO (International Standards Organization) offer Kenya convenient solutions that will not only respond to the local and global market demands, but also be a panacea to the technological problems that it encounters. No country can successfully develop without addressing the critical issue of demand and supply on energy [6].

Kenya is in a very interesting development phase with regards to its domestic energy requirements. In the past decade the country has grappled with the challenge of unreliable, expensive and unsustainable energy use supporting a stagnating industrial and manufacturing base [6]. The recent population census held in Kenya in 2009 as reported by Kenya National Bureau of Statistics (KNBS) shows that the Kenyan population has been increasing on average by one million per year. Currently, Kenya is grappling to supply the ever rising energy demands to its ever increasing population. Distribution and transmission losses remain an important issue as the rate of loss verged on $17 \%$ in 2012. Electricity consumption reached 6,581GWh in $2012 / 13$, increasing by $73 \%$ from $2007 / 08$. The high cost of energy is one of the biggest bottlenecks to economic activity in the country [7]. Kenya continues to lose out on foreign direct investments partly because of this problem, with considerable penalties on socio-economic development.

As a consequence, the economy experiences high electric power system losses estimated at $20 \%$ of net generation, extreme voltage fluctuations and intermittent power outages at 11,000 per month, which cause material damage and losses in production. Given the above scenario organizations are encouraged to adopt ISO 9001 requirements in their management systems so as to improve performance [8] and avoid losses attributed to unreliable energy source challenging development of the government. An organization which is certified to ISO 9001 is expected to enhance customer satisfaction and consistently provide products that meet customer and applicable statutory and regulatory requirements. So far studies accessed by the researcher on quality management systems in Kenya focus on health sector $[9,10]$, education $[11,12]$, banking sector [11] and wildlife services [13]. The paper seeks to find out how quality management systems affect organizational performance through an extant multidisciplinary literature review. The focus was mainly customer on customer satisfaction, employee engagement, productivity and management control. The paper proposes a theoretical model which scholars and researchers can test empirically in the field of quality management systems. Organizations will also benefit from the details of the paper hence improve their quality management systems in place for better organizational performance.

\section{Literature Review}

TQM is an ideology which is focused on the satisfaction of customer's need. Thus, most organizations try as much as possible to meet or exceed customer's expectation in their daily activity and also their long term plan [14]. TQM require organizations to develop a customer focused operational processes and at the same time committing the resources that position customers and meeting their expectation as an asset to the financial well-being of the organization. Andrle [15] explains that it is necessary for organizations to maintain a close link with their customers in order to know their requirements and to measure how it has been successful in meeting up to customers' requirements. According to [16] a high level of customer satisfaction is obtained solely by providing services or products whose features will satisfy customer's requirements or needs. The customer's needs and expectations serve to drive development of new service offering. This is due to the fact that customers determine the quality level of service delivered [17].

Oakland [18] noted that organizations are made up of a series of internal suppliers and customers. To him, this forms the quality chain of the company and it implies that every employee is a potential customer and supplier in the course of production. The process of production is structured in a way where each process have needs and expectations which must be fulfilled by others in the network of production. The effective fulfillment of these needs leads to the production of quality goods and services.

In recent years there has been a weight of evidence suggesting that engagement has a significantly positive impact on productivity, performance and organizational 
advocacy, as well as individual well-being, and a significantly negative impact on intent to quit and absenteeism from the work place. The potential for employee engagement to raise levels of corporate performance and profitability has been noted by government and policymakers as well, and has led in the UK, for instance, to the highly influential work of Engage for Success a voluntary movement involving public, private and third sector employers, alongside representatives from government, trades unions and professional bodies, as well as consultants and academics. The espoused aim of the movement is to provide employers with free tools, techniques and guidance on how to raise the engagement levels of workers, based on the premise that a highly engaged workforce will perform better than one that is disengaged, as well as enjoying higher levels of personal well-being, thus ultimately helping bolster the UK economy [19].

Eatwell and Newman [20] defined productivity as a ratio of some measure of output to some index of input use. Put differently, productivity is nothing more than the arithmetic ratio between the amount produced and the amount of any resources used in the course of production. This conception of productivity goes to imply that it can indeed be perceived as the output per unit input or the efficiency with which resources are utilized. In effect, productivity becomes the attainment of the highest level of performance with the lowest possible expenditure of resources. It represents the ratio of the quality and quantity of products to the resources utilized. In a nutshell, productivity is concerned with efficiency and effectiveness simultaneously. Lawlor [21] sums up productivity as comprehensive measures of how efficient and effective an organization or economy satisfies five aims: objectives, efficiency, effectiveness, comparability and progressive trends. No matter how it is perceived, productivity implies that there is an incremental gain in what is produced as compared with the expenditure on measures utilized.

Performance management system (PMS) can be defined as the set of the evolving formal and informal mechanisms, processes, systems, and networks used by organizations for conveying the key objectives and goals elicited by management, for assisting the strategic process and ongoing management through analysis, planning, measurement, control, rewarding, and broadly managing performance, and for supporting and facilitating organizational learning and change [22]. The main characteristics of this definition refers to different types of mechanisms (both formal and informal); the effectiveness in strategy accomplishment; the PMS' purpose, i.e. enabling the organization to achieve its goals, through learning and change.

Performance measurement is an integral part of all management processes and traditionally has involved management accountants through the use of budgetary control and the development of financial indicators such as return on investment. However, it has been claimed that conventional aggregate financial accounting indicators are inappropriate in TQM settings. Several authors have claimed that an important part of ensuring that TQM leads to sustained improvements in organizational profitability is that direct quantitative measures of manufacturing are used to assess the effectiveness of managers' efforts to manage the development and implementation of TQM programmes. TQM has evolved as a philosophy that emphasizes the need to provide customers with highly valued products and to do so by continuous improvement. While TQM provides a potential for organizations to enhance their competitiveness there is evidence that many organizations have been disappointed [23]. Performance management systems are a cornerstone of human resource management practices and are the basis for developing a systems approach to organization management. In theory, a performance management system links organizational and employee goals through a goalsetting process, and subsequently links employee goal achievements to a variety of HR management decisions through a performance measurement process.

\section{Emerging Issues}

A study carried out by Kimutai [10], indicate that quality management systems (QMS) has prompted prompt delivery of services to customers consistently both day and night. It has also led to consistent presence of health workforce at service delivery points resulting in an increased number of customers served. This is also reaffirmed in a study done by Karani and Bichanga [11] whereby Kenya Wildlife Services (KWS) employees maintained that the organization should understand the current and future needs of customers and that business performance and customer satisfaction are enhanced by quality management practices. A study by Bichanga et al, [13] established that service delivery in most of the Kenyan universities was average and that ISO (International Standards Organization) certification affected service delivery to a great extent.

One of ISO 900 standard requirements is employees' extensive continuous training on core knowledge of their jobs skills and competency [10]. Adoption of Quality Management Systems had ensured consistent training and therefore improved performance of health workers in their institutions. The findings also agree with results in a study done by Otieno and Kinuthia [9], on Total Quality Management practices in selected private hospitals in Nairobi, Kenya who found out that training on Total Quality Management practices would go a long way in eliminating information asymmetry since its success is highly dependent on information dissemination and feedback across all levels of an organization. The results in a study by Bichanga et al., [13] also revealed that ISO 9001:2008 certification defines responsibilities clearly, improves communication within the universities, facilitates data gathering for management, improves the attitude of the staff, improves staff management, improves integration within the university and reduces improvisation.

A study done by Mangula [24] revealed that the quality of products in manufacturing firms in Tanzania had 
significantly improved following the adoption and being certified by ISO 9001 . More specifically the findings depict that quality product had improved in terms of reduced customer complaints' and the ability of product to meet the local and international standards.

Research findings done by Oluwatoyin and Oluseun [25], attest to the benefits that accrue from the implementation of Total Quality Management as a strategic tool for an organization to employ in the quest to remain competitive. If adequately deployed, the principle brings about added value to an organization in terms of efficiency in operation, employee satisfaction, customer satisfaction, and even profitability. The findings also revealed that the relentless pursuit of improvement in service delivery bring about added value to customers by making the organization focused on satisfying customers' needs, while team work and training empowers employees for the continuous improvement drive of the organization. The implication of managing every facet of the organization was revealed, as each production unit is seen to affect and in turn affected by others. That is, a dysfunction in the process of service delivery has an overall effect on the total production process, thus showing the need for a holistic approach which involves every functional area to be managed effectively.

\section{Review of Supporting Theories}

Oliver $(26,27)$ proposed the Expectancy-Disconfirmation Paradigm (EDP) as the most promising theoretical framework for the assessment of customer satisfaction. The model implies that consumers purchase goods and services with pre-purchase expectations about the anticipated performance. The expectation level then becomes a standard against which the product is judged. If the outcome matches the expectation confirmation occurs. Disconfirmation occurs where there is a difference between expectations and outcomes. A customer is either satisfied or dissatisfied as a result of positive or negative difference between expectations and perceptions.

Catherine et al [19] examined the implications of engagement within the context of human resource development (HRD). HRD is concerned with the development of both human and social capital within the organization, and there has been increasing focus in recent years on the relevance of engagement in enhancing individual performance and the individual experience of work. They highlight the emerging definition of engagement within the HRD field as being the cognitive, emotional and behavioural energy an employee directs towards positive organizational outcomes. They highlight the role that HRD can play not only in raising levels of engagement, but also in reducing levels of disengagement. This can be indicated through organizational development, workplace learning and career development initiatives.

The growth accounting framework acts as a mechanism for breaking down the sources of economic growth into the contributions from increases in capital, labour and other factors. When these factors have all been accounted for, what remains is usually attributed to technology. This remainder is often called the Solow residual and, in theory, if all the factors contributing towards productivity were identified and measured correctly then this residual would be zero. The growth accounting framework is the main framework used internationally and is now more than fifty years old. [28, 29].

Systems theory consists of five components namely: inputs, a transformation process, outputs, feedback and the environment. Inputs are the material, human, financial or information resources used to produce goods and services. Transformation process is managements' use of production technology to change the inputs into outputs. Outputs include the organizations' products and services. Feedback is knowledge of the results that influence the selection of inputs during the next cycle of the process. The environment surrounding the organization includes the social, political and economic forces [30]).

\section{Proposed Theoretical Framework}

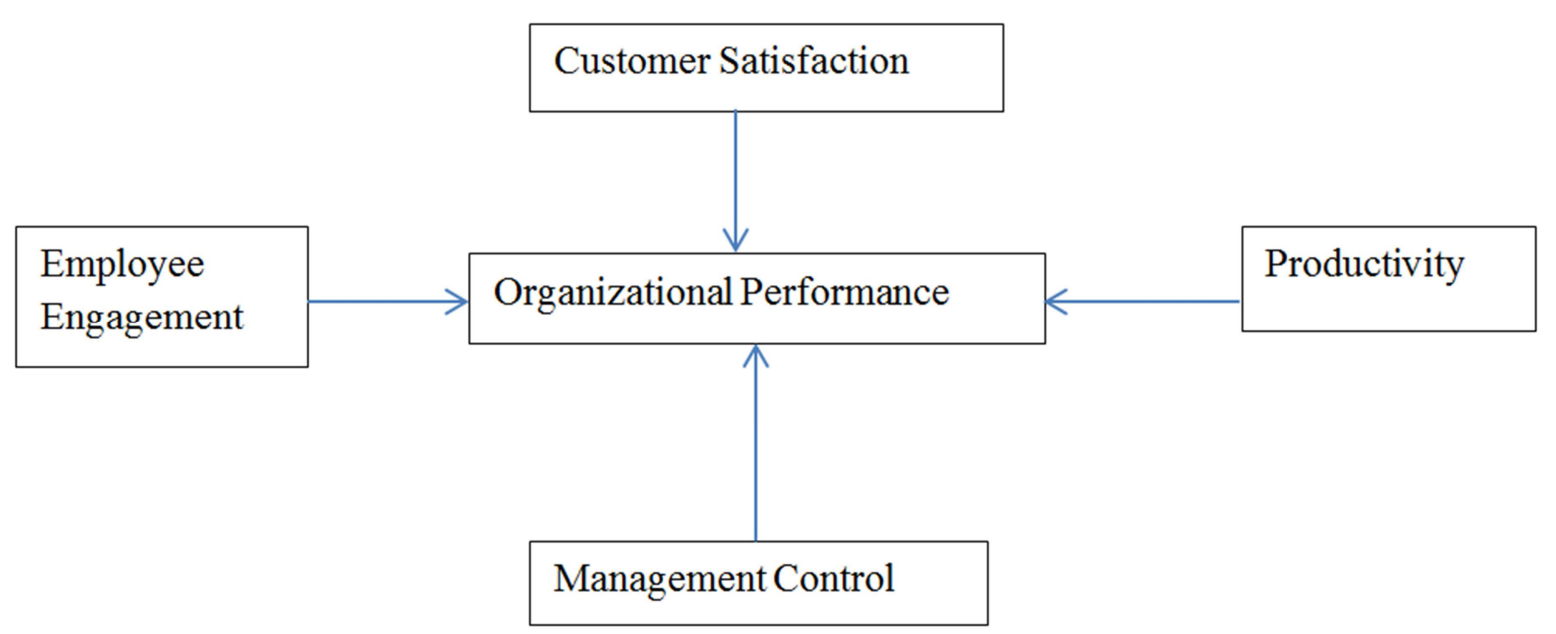

Figure 1. Proposed theoretical framework relating quality management and organizational performance. 
Customer satisfaction refers to a person's feeling of pleasure or disappointment which results from comparing a product's perceived performance or outcome against his or her expectations [30].

Employee engagement is defined as positive attitude held by the employee towards the organization and its value. An engaged employee is aware of business context, and works with colleagues to improve performance within the job for the benefit of the organization. The organization must work to develop and nurture engagement, which requires a twoway relationship between employer and employee [31].

Productivity refers to the attainment of the highest level of performance with the lowest possible expenditure of resources. It represents the ratio of the quality and quantity of products to the resources utilized [32].

Management control is defined as a systematic effort by an organization to compare performance to predetermined standards, plans, or objectives in order to determine whether performance is in line with these standards and presumably in order to take any remedial action required [22].

Organizational Performance refers to the actual output or results of an organization measured against its intended goals and objectives. According to Richard et al. [33] organizational performance encompasses three specific areas of firm outcomes: financial performance which comprise profits, return on assets and return on investment; product market performance for example sales and market share; and shareholder return focusing on total shareholder return and economic value added.

\section{Conclusion and Recommendations}

Overall extant literature indicate that adoption of quality management systems has resulted to prompt delivery of services, quality of the products had improved in terms of reduced customer complaints' and the ability of product to meet the local and international standards. Further studies shows that ISO 9001:2008 certification defines responsibilities clearly, improves communication within the universities, facilitates data gathering for management, improves the attitude of the staff, improves staff management and improves integration. ISO certification also ensured consistent training and therefore improved performance. Quality Management Systems implementation has positive effects on overall organizational performance and implementing does pay off since the benefits accrued include; improved quality, employee satisfaction, productivity, employee participation, teamwork, communication, profitability and greater market share.

The idea behind the implementation of quality management systems is to ensure that adequate attention is given to quality so as to give room for an error free transactional process and less room for customer complaints while maximizing customer satisfaction. It is proven that satisfied customers are more willing to recommend quality service to others. This has some cost reduction implication on the organizations which is good for the business as they will be able to compete more effectively in terms of operating cost. In summary, quality is defined in the eyes of consumers, thus a customer focus approach which total quality management emphasizes, keeps organizations abreast of how customers define it from time to time.

Being a theoretical paper, the findings lack an empirical perspective. Therefore, it is highly recommended that further longitudinal research is carried out to find out why quality ISO 9001 certified government organizations in Kenya are facing challenges in meeting the expectations of their customers in service delivery.

\section{References}

[1] Arauz, R. \& Suzuki, H. (2004). ISO 9000 Performance in Japanese industries, Total Quality Management and Business Excellence Journal, Routledge, 15 (1).

[2] Hendricks, K. B. \& Singhal, V. R. (2001). Firm characteristics, total quality management, and financial performance, Journal of Operations Management, 19 (3).

[3] Lakhal L. (2014). The Relationship Between ISO 9000 Certification, TQM Practices, and Organizational Performance.

[4] International Standards Organization (2013b) available at: www.iso.org/iso/home/standards/certification/isosurvey.htm?c ertificate $=\mathrm{ISO} \% 209001 \&$ count

[5] Standards and global trade: A voice for Africa (2003), World Bank.

[6] Institute of Economic Affairs (2015). Situational Analysis of Energy Industry, Policy and Strategy for Kenya;

[7] Government of Kenya (2012). National Energy Policy (Third Draft). Ministry of Energy. Government printer, Nairobi.

[8] ISO (2008), ISO 9001: 2008 Quality management systems Requirements, ISO Switzerland, 4th Edition.

[9] Otieno, E, A, \& Kinuthia, D, M. (2013). Total Quality Mangement Practices in selected Private Hospitals in Nairobi, Kenya. European Journal of Business Management, 5 (13).

[10] Kimutai, G., (2014). Role of QMS certification factors on health workforce performance in Kenyan Referral Hospitals. JKUAT doctoral thesis.

[11] Bichanga W. O., \& Annie W. K. (2013). Effectiveness of ISO 9001:2008 Certification On Service Delivery Of Public Universities In Kenya European Journal of Business and Management, 5 (13).

[12] Okwiri, A, O. (2013). ISO 9001 Quality Management Systems Audit as an Organizational Effectiveness Evaluation Tool. International Journal of Information Technology and Business Management, 20 (1).

[13] Bichanga, W, O. \& Karani, S. R. (2012). Effects of Total Quality Management Implementation on Business Performance in Service Institutions. A Case of Kenya Wildlife Services. International Journal of Research Studies in Management, 1 (1). 
[14] Andrle, J. (1994), 'Total Quality Management in Public Transportation', Research Result Digest, 3.

[15] Filppini, R. \& Forza, C. (1998), 'TQM Impact on Quality Conformance and Customer Satisfaction: A Causal Model', International Journal of Production Economics, 55 (1).

[16] Muffato, M., \& Panizzolo, R., (1995). A Process Based View for Customer Satisfaction, International Journal of Quality and Reliability Management, 12 (9).

[17] Jablonski, J., (1992), Implementing TQM; Competing in the Nineties through Total Quality Management, 2edn, San Diego, Pfeiffer.

[18] Oakland, J. S., (1993). Total Quality Management: The Route to Improving Performance, 2edn, Oxford, Butterworth Heinemann Ltd.

[19] Catherine T, Rick D, Kerstin A, Amanda S, \& Emma S, (2014). Employee Engagement in Theory and Practice. Routredge, NY.

[20] Eatwell, J. M. \& Newman, P. (1991). The New Palgrave: A Dictionary of Economics vols. 3, 4.\& 12, Macmillan, Tokyo.

[21] Lawlor, A. (1985). Productivity Improvement Manual. Aldershot, United Kingdom.

[22] Ferreira A, Otley D (2009). The design and use of performance management systems: an extended framework for analysis. Manage Account Res, 20.

[23] Wilson, D. C., 1992. A Strategy of Change, London, U. K., Routledge.

[24] Mangula, M, S, (2013). Effect of Quality Management Systems (ISO 9001) Certification on Organizational Performance in Tanzania: A Case Of Manufacturing Industries In Morogoro. International Journal of Technology Enhancements and Emerging Engineering Research, 1 (1).
[25] Oluwatoyin, A. \& Oluseun, A. (2008). Total Quality Management. A Test of the Effect of TQM on Performance and Stakeholder Satisfaction. Blekinge Institute of Technology.

[26] Oliver, L. R. (1977). Effect of expectation and disconfirmation on post exposure product evaluations: an alternative interpretation, Journal of Applied Psychology, 62 (4).

[27] Oliver. R. L. (1980). A Cognitive Model of the Antecedents of Satisfaction Decisions, Journal of Marketing Research, (17).

[28] OECD (2001a). Measuring Productivity: OECD Manual, Organization for Economic Co-operation and Development: Paris.

[29] OECD (2001b). Measuring Productivity: OECD Manual, Organization for Economic Co-operation and Development: Paris.

[30] Kotler, P \& Keller, K, 2006, "Marketing Management", twelfth edition, Prentice-Hall.

[31] Robinson D., Perryman S., \& Hayday S. (2004). The Drivers of Employee Engagement Report 408, Institute for Employment Studies, UK.

[32] Amadi, A. O. (1991) "Recipe for Productivity Improvement" in Umeh, P. O. C. et al (1991) "Increasing Productivity in Nigeria" Proceedings of the First National Conference on Productivity 1 sty $3^{\text {rd }}$ December 1987 , National Productivity Centre, Macmillan, Nigeria.

[33] Richard et al. (2009): Measuring Organizational Performance: Towards Methodological Best Practice. Journal of Management. 